\title{
RESISTÊNCIA E CRIATIVIDADE: EXPERIÊNCIAS DE SUBJETIVAÇÃO E SAÚDE NO TRABALHO DE MÉDICOS DO SUS, EM BELO HORIZONTE
}

RESISTANCE AND CREATIVITY: EXPERIENCES OF SUBJECTIVATION AND HEALTH IN THE WORK OF PHYSICIANS OF SUS, IN BELO HORIZONTE

RESISTENCIA Y CREATIVIDAD: EXPERIENCIAS DE SUBJETIVACIÓN Y SALUD EN EL TRABAJO DE MÉDICOS DEL SUS, EN BELO HORIZONTE

\author{
Crisane Costa Rossetti* \\ José Newton Garcia de Araújo ${ }^{* *}$
}

\begin{abstract}
RESUMO
Este artigo pretende identificar os movimentos de resistência no contexto de trabalho dos médicos que atuam no Programa Saúde da Família (PSF), do Sistema Único de Saúde (SUS), em Belo Horizonte. A resistência emerge como experiência de criatividade e subjetivação, no sentido proposto por Françoise Proust, em convergência com autores da Psicossociologia do Trabalho e de outras abordagens clínicas do trabalho. A partir de entrevistas com médicos do PSF, as análises sugerem que as formas de resistência se opõem às atitudes de impessoalidade, indiferença e distanciamento dos princípios e diretrizes do SUS, além de funcionar como estratégias de ação que revertem em saúde para o trabalhador. Tais estratégias são determinantes para manter o funcionamento do Sistema e para garantir aos cidadãos o direito de assistência à saúde, de forma universal, equânime e integral.
\end{abstract}

Palavras-chave: Trabalho. Resistência. Subjetivação. Criatividade. SUS.

\begin{abstract}
This article intends to identify movements of resistance in the work of the physicians who work in the Family Health Program (PSF) of the Unified Health System (SUS), in Belo Horizonte. Resistance emerges as an experience of creativity and subjectivation, as proposed by Françoise Proust, in convergence with authors of the Work Psychosociology and other clinical approaches to work. From interviews with PSF physicians, the analyzes show that the forms of resistance are opposed to the attitudes of impersonality, indifference and distancing of the principles and guidelines
\end{abstract}

\footnotetext{
* Psicólogo, mestre em Psicologia pela Universidade Federal de Minas Gerais. Doutoranda em Psicologia pela PUC Minas. Psicóloga da Secretaria Municipal de Saúde de Belo Horizonte, consultora na área de Psicologia do Trabalho e Intervenção Psicossocial.E-mail: crisanec@hotmail.com

** Doutor em Psicologia Social e Clínica pela Universidade de Paris 7, mestre em Filosofia pela UFMG, psicólogo, professor da PUC Minas, pesquisador do CNPq, bolsista PPM pela Fapemig. E-mail: jinga@uol.com.br
} 
of the SUS, besides acting as action strategies that benefit worker health. Such strategies are decisive for maintaining the functioning of the System and for guaranteeing citizens the right to universal, equitable and integral health care.

Keywords: Work. Resistance. Subjectivation. Creativity. SUS.

\section{RESUMEN}

Este artículo pretende identificar los movimientos de resistencia en el contexto de trabajo de los médicos que actúan en el Programa Salud de la Familia (PSF), del Sistema Único de Salud (SUS), en Belo Horizonte. La resistencia emerge como experiencia de creatividad y subjetivación, en el sentido propuesto por Françoise Proust, en convergencia con autores de la Psicosociología del Trabajo y de otros abordajes clínicos del trabajo. A partir de entrevistas con médicos del PSF, los análisis sugieren que las formas de resistencia se oponen a las actitudes de impersonalidad, indiferencia y distanciamiento de los principios y directrices del SUS, además de funcionar como estrategias de acción que revierten en salud para el trabajador. Estas estrategias son determinantes para mantener el funcionamiento del sistema y para garantizar a los ciudadanos el derecho de asistencia a la salud, de forma universal, equitativa e integral.

Palabras clave: Trabajo. Resistencia. Subjetivación. Creatividad. SUS.

\section{INTRODUÇÃO}

A proposta brasileira de levar assistência à saúde a mais de 100 milhões de $\triangle$ pessoas, de forma integral e gratuita, destaca-se pela singularidade e pelo Idesafio que ela impõe, desde o seu início: sustentar um novo conceito de saúde, no qual se inclui uma dimensão política, num cenário em que a ideologia neoliberal se expandia pelo Brasil e pelo mundo, desde os anos de 1980 . Qualquer resgate da história do Sistema Único de Saúde (SUS) mostrará que ele se fundou, e mantém-se ainda, em ações de resistência que se manifestam não apenas no âmbito dos movimentos sociais, como também dos espaços em que o trabalho acontece.

Referimo-nos ao conceito de resistência tal como desenvolvido pela filósofa francesa Françoise Proust, o que nos ajuda a elaborar uma releitura ampliada dos sentidos que o conceito pode abranger. O objetivo deste artigo é identificar os movimentos de resistência, no contexto de trabalho dos médicos que atuam no Programa Saúde da Família (PSF), no âmbito do SUS, na cidade de Belo Horizonte, campo no qual desenvolvemos uma pesquisa de doutorado. 


\section{O SISTEMA ÚNICO DE SAÚDE DO BRASIL E A ESTRATÉGIA SAÚDE DA FAMÍLIA ${ }^{1}$}

O SUS foi criado em 1988, resultado de uma história de lutas sociais por melhores formas de vida. Sua proposta foi consolidada, a partir dos movimentos sociais, por uma Reforma Sanitária que se caracterizou, sobretudo, como um movimento político pela democracia, por um projeto de sociedade mais justa, de um povo que resistia a viver sob condiçóes opressivas, de medo e iniquidade.

Após a abertura política em 1985, a saúde é legitimada pela nova Constituição de 1988 como direito de todos e dever do Estado; em 1990, o SUS é implantado, com a proposta de transformar a assistência à saúde em direito de cidadania, mas, nesse mesmo ano, vivemos a ascensão do governo Fernando Collor de Melo, que considerava o SUS "uma excrescência" (Arouca, 2003, p. 2). A expansão da ideologia neoliberal, não apenas no Brasil como também no mundo, já se impunha de forma insidiosa, levando ao enfraquecimento dos interesses públicos e dos valores coletivos.

Pode-se afirmar que os movimentos pela construção e as estratégias de desconstrução do SUS sempre coexistiram. As forças políticas e econômicas que se opõem ao sistema público forjam emendas constitucionais e discursos de desqualificação do SUS, que tendem a acirrar, cada vez mais, o embate com os movimentos instituintes, que ainda lutam pelos direitos de cidadania, pela universalidade e equidade da assistência à saúde.

Em Belo Horizonte a Estratégia da Saúde da Família foi implantada em 2002, inicialmente em Unidades Básicas de Saúde (UBS), em territóriosalavras classificados como de alto Índice de Vulnerabilidade à Saúde (IVS) ${ }^{2}$. Esse novo modelo assistencial define mudanças estruturantes na organização do trabalho e na forma de atendimento aos usuários, a partir da Atenção Básica. A proposta é que a ação deixe de ser apenas curativa, na assistência a pessoas passivas que procuram as Unidades somente quando apresentam alguma doença ou sintoma. Devem-se desenvolver ações curativas, quando necessário, mas sobretudo ações e mudanças de comportamento, nos campos da prevenção e da promoção da saúde, de forma a agenciar maior autonomia dos sujeitos em seus modos de caminhar na vida e de exercer a cidadania.

\footnotetext{
1 O Programa Saúde da Família (PSF) foi criado em 1994, mas, devido à sua amplitude e centralidade como modelo norteador da proposta de reorganização da Atenção Primária, foi redefinido como Estratégia em 1997. (Tostes, Reis, \& Pitchon, 2012; BRASIL, 2012). Neste estudo, referimo-nos ao "programa" PSF enquanto campo de atividades desenvolvidas pelos trabalhadores, inserido na "estratégia" (ESF), enquanto modelo de política de atenção à saúde.

2 Esse indicador foi criado em 1998 e utilizado como referência pela Secretaria Municipal de Saúde de Belo Horizonte, com o objetivo de apontar o nível de vulnerabilidade da saúde da população, num determinado território. Trata-se de um "Indicador de Risco", associado a outros indicadores do IBGE, como moradia, educação, saneamento, renda e mortalidade infantil. Assim, os territórios foram classificados como de baixo, médio, elevado ou muito elevado risco. (Rates et al., 2012).
} 
Embora as equipes que atuam na Estratégia Saúde da Família (ESF) sejam multidisciplinares, nossa pesquisa faz um recorte, focalizando a categoria dos médicos. A investigação deixa evidente que o trabalho no PSF está se precarizando, em função das estratégias de "desmonte" do sistema e da consequente deterioração das condiçôes de trabalho, que atinge a categoria dos médicos.

\section{RESISTÊNCIA E TRABALHO NO SUS}

Ao longo dos quase trinta anos de existência do SUS, os movimentos de resistência sempre estiveram presentes, através de resistências sindicais, ainda que enfraquecidas, ou de resistências locais, individuais ou coletivas, que se insurgem nos processos de trabalho, nos espaços e contextos em que ocorrem, cotidianamente, as negociações mais ou menos implicadas nos processos de cuidado e atenção à saúde. Com efeito, a confrontação entre o que está prescrito no trabalho do médico e a realidade do PSF tanto pode levar à desistência, quanto à criação de estratégias defensivas, ou a movimentos criativos de construção de alternativas que mantenham esses trabalhadores no SUS.

Retomamos o conceito de resistência, segundo Françoise Proust (1997). A autora afirma que a resistência é imanente ao sujeito, um acontecimento, um ato que não acontece por obrigação ou como resultado de um acontecimento, em resposta a uma ação agressiva; ao contrário, é uma força que sempre esteve ali, nos territórios mais ou menos distantes, subjetivos e concretos, do ser vivente.

A resistência no trabalho manifesta-se diante de situações em que, para o trabalhador, não é mais possível manter-se numa condição de assujeitamento em relação às violações de sua ética, de seus valores e de seu saber-fazer. Lhuilier e Roche (2009) destacam que "resistir significa opor uma força a outra, que tende a destruir nossa energia para o trabalho; significa salvar, a qualquer custo, o corpo que contém essa energia ou, pelo menos, retardar o tempo de desgaste e, num prazo maior, salvá-lo do esgotamento, da destruição" (p. 12). Resistir é agir, no sentido da transformação, frente a um real que ameaça cercear e dominar o espaço subjetivo e intersubjetivo, sobre o qual incidem relações de poder e dominação.

Nesse sentido, todo movimento de resistência implica uma subversão e uma experiência de liberdade do ato, na escolha das estratégias de luta e na criação de outros rumos possíveis. Liberdade que insiste e não se curva às intransigências das formas de governo sobre os homens. Dito de outra forma, a resistência é parte de um processo de subjetivação (Proust, 1997). Ela tanto pode apresentar uma face de atividade quanto de reatividade. Para Foucault, resistir é o oposto de reagir. "Quando reagimos, damos a resposta àquilo que o poder quer de nós; mas quando resistimos criamos possibilidades de existência a partir de composições 
de forças inéditas. Resistir é, neste aspecto, sinônimo de criar" (Maciel Júnior, 2013, p. 2). Há aqui uma afinidade com o pensamento de Proust (2000, como citada em Bampi, 2002), quando a autora afirma que há resistências reativas que não visam à transformação do estado das coisas, enquanto as resistências ativas se fundam na invenção e na afirmação de algo novo, potencializando o agir humano a favor da vida e da liberdade.

Ambivalente em vários aspectos, a resistência comporta a vida e a morte, o exterior e o interior dos sujeitos e das forças que enfrentam. No ato de resistência, o sujeito delibera por agir de uma forma ou outra, avançar ou recuar diante de acontecimentos que podem transformar as diversas situaçôes vividas em seu cotidiano. Ela se exerce nos atos diários, nas arbitragens e nas situações imprevistas que singularizam o trabalhador e o convocam a responder como sujeito. Nessa perspectiva, a resistência cria possibilidades para a emergência do sujeito da ação, abre espaços para o devir e para a irrupção de outras formas de interações e negociações sociais (Proust, 1997; Fleury, 2009).

Nas unidades de saúde, buscadas por um grande contingente de usuários, tanto maior quanto mais se agrava e se estende a crise política e econômica no Brasil, os médicos se angustiam e se veem diante de demandas conflitantes. De um lado, eles são cobrados pela gestão para cuidar do maior número de pessoas, para cumprir protocolos e atingir metas definidas por técnicos que parecem desconhecer o contexto real do trabalho e as reais necessidades da população daquele território, bem como a capacidade e os recursos concretos das equipes de saúde.

E, por outro lado, frente a uma realidade marcada pela carência, em suas múltiplas dimensões, a população, que não porta apenas as dores do corpo, demanda da unidade de saúde ser também acolhida em sua dor de viver. $\mathrm{Na}$ escuta do usuário, o trabalhador da saúde experimenta um sofrimento específico, melhor dizendo, ele tem que se confrontar com a falta dos diversos determinantes sociais de saúde para a população, tais como educação, lazer, trabalho, segurança, direitos de cidadania, enfim, condições dignas de vida. Assim, os médicos do PSF relatam sentimentos de impotência, mesclados aos de falta de reconhecimento institucional e à indignação, relativa aos discursos das esferas políticas e econômicas que desqualificam o trabalho, o trabalhador e os usuários do SUS. Nesse campo paradoxal em que se manifesta a tendência à instrumentalização da vida, em contraposição ao atendimento humanizado e à solidariedade, o médico investe na responsabilização e na busca de autonomia, junto ao usuário, bem como na escolha das alternativas de cuidado. $\mathrm{O}$ debate entre o uso de si por si e o uso de si pelos outros (Schwartz, 2011) pode, então, atingir dimensões inegociáveis, e é aí que se revelaria a resistência. 


\section{METODOLOGIA}

Neste estudo optamos por uma abordagem metodológica qualitativa. Como procedimentos para coleta de dados, utilizamos entrevistas individuais em profundidade, observação e diário de campo. Foram convidados a participar das entrevistas 26 médicos do PSF. Com o objetivo de abranger toda a cidade e territórios com características distintas, tomamos como referência a classificação por IVS: de baixo ou médio risco, elevado e muito elevado risco. Assim, participaram três médicos de quase todas as regionais de Belo Horizonte ${ }^{3}$. Em apenas uma contamos com a participação de dois profissionais.

Por ser a pesquisadora também servidora do SUS, que presta atendimento aos trabalhadores da rede, os sujeitos foram escolhidos pela Gestão do Trabalho de cada regional, segundo os seguintes critérios: que não tivessem sido atendidos previamente pela pesquisadora; que fossem profissionais efetivos, já tendo cumprido o estágio probatório ${ }^{4}$ de três anos; que vinham se mantendo frequentes no trabalho.

Entendemos a análise dos dados como um processo complexo, em que se encontram envolvidas, no caso deste estudo, pelo menos três instâncias: a pesquisadora, os sujeitos pesquisados e o trabalho de ambos - dos médicos e da pesquisadora. Ela e eles, cada qual a seu modo, trazem em si um acervo de informações, saberes e construções conceituais, técnicas e ideológicas, que têm suas origens nas próprias histórias, bem como na relação com o trabalho e com o seu contexto. $\mathrm{O}$ trabalho da análise baseada, em princípio, no discurso dos participantes constitui um novo texto, produzido a partir da interpretação da pesquisadora. Essa análise compreende, pois, as variáveis relacionadas acima, entre as quais ressaltamos, no ato da interpretação, a implicação da pesquisadora.

Se esse novo texto tem como desafio aproximar-se, enquanto possível, do trabalho real e da resistência dos médicos, por mais que estes falem, não conseguirão abarcar totalmente a situação abordada. Ao mesmo tempo, a implicação da pesquisadora incide, pelo menos parcialmente, em sua atividade interpretativa. Isso implica, ainda que se tente ancorar nas orientações metodológicas, um trabalho suplementar e permanente, que é a análise da própria implicação.

Estabelece-se, então, nesse processo, o encontro entre a palavra que falta, no discurso do médico do PSF e no texto da pesquisadora, na produção de sua análise. E aqui poderíamos evocar um outro tipo de resistência, no sentido do "desconhecimento", da denegação, do próprio encontro (inexistente?) com essa

3 Belo Horizonte é dividida em nove regionais, ou distritos sanitários: Barreiro, Oeste, Leste, Centro-Sul, Norte, Venda Nova, Pampulha, Nordeste e Noroeste.

4 Estágio probatório corresponde aos três anos iniciais do servidor em exercício no serviço público, nos quais ele se encontra em um período de "experiência" e avaliação. Somente após cumpridos os três anos ele adquire a estabilidade. 
palavra que falta. Isso remete, pois, tanto à resistência do sujeito, relativa ao ato de seu ofício, quanto à resistência da pesquisadora, no ato da análise. No entanto, é justamente nessa lacuna que pode emergir o fazer criativo, igualmente necessário à cientificidade da pesquisa e à produção do conhecimento.

$\mathrm{Na}$ análise dos dados, utilizamos a análise temática que, segundo Bardin (2011), trabalha a presença e a frequência com que alguns temas emergem nos discursos. Trata-se de uma leitura que visa identificar categorias ou expressóes sob as quais se organizam os depoimentos, tais quais eles são apresentados. Cabe, então, ao pesquisador propor interpretações, inter-relacionando-as ao arcabouço teórico utilizado, ou mesmo propor outras bases de interpretação que possam emergir a partir dos relatos em análise (Minayo, 2010).

\section{ANÁLISE DOS DADOS}

Entre os médicos entrevistados, 13 são homens e 13 são mulheres. A equiparação de gênero, entretanto, não foi intencional, lembrando que os convites foram feitos em nove regionais diferentes, por pessoas diferentes. Vale registrar que a pesquisa de campo foi feita, em sua maioria, no período em que Belo Horizonte passava por intensa epidemia de dengue, de novembro de 2015 a maio de 2016, o que foi um fator dificultador no agendamento das entrevistas. Por mais que houvesse interesse do médico em participar da pesquisa, várias entrevistas foram canceladas ou adiadas devido ao grande número de casos que, frequentemente, extrapolavam a capacidade das equipes de saúde, levando-as a trabalhar à quase exaustão, conforme foi relatado por médicos e outros trabalhadores. Além disso, muitos médicos também contraíram a doença.

As entrevistas foram gravadas e, em seguida, transcritas na íntegra. Os nomes dos participantes foram substituídos por nomes fictícios, com o objetivo de preservar o sigilo garantido no TCLE. As entrevistas foram agendadas nos centros de saúde, durante o horário de trabalho, em algum momento em que o médico pudesse interromper, ou suspender, por algum tempo, suas atividades.

A partir dos dados produzidos pelos sujeitos, destacam-se elementos comuns, relativos ao contexto de trabalho, que abrangem não apenas as condiçōes físicas e estruturais dos centros de saúde, como as relações formais e informais que se estabelecem entre sujeitos, entre sujeitos e organização, as relações de poder, e entre sujeitos e a atividade. Esse cenário onde o trabalho acontece não deve ser analisado apenas à luz das prescrições, das tarefas e das situações concretas do campo. Às condições de trabalho devem-se acrescentar as relações subjetivas e intersubjetivas que povoam o cotidiano da Unidade, que convocam, de forma mais ou menos incisiva, o poder de ação e a resistência do trabalhador. 
Neste artigo, apresentamos resultados parciais da pesquisa. Serão destacados relatos de apenas quatro participantes que atuam com populações de diferentes IVS: um de baixo risco, um de elevado e dois de muito elevado risco.

No que tange à estrutura física e ao ambiente de trabalho, percebemos que as Unidades visitadas não seguem um mesmo padrão. Encontramos desde Centros de Saúde em estado muito precário, com pouca ventilação e iluminação, presença de escadas sem acessibilidade para pessoas portadoras de deficiência ou com restrições osteo-musculares, além de número insuficiente de consultórios e salas. Outros foram reformados ou construídos a partir do Orçamento Participativo, apresentando uma estrutura física ampla e adequada. Quanto a equipamentos e instrumentos de trabalho, destacam-se cadeiras defeituosas, aparelhos e instrumentos de trabalho quebrados ou inexistentes, impressoras barulhentas que podem causar perda auditiva, segundo relatos da maioria dos sujeitos, além dos ruídos do ambiente que podem desencadear stress.

Embora o salário da categoria médica seja mais alto em relação ao dos demais trabalhadores da saúde, muitos avaliam que não recebem uma remuneração justa ou equiparada à de seus colegas que atuam no sistema privado. Mas não há uma percepção comum em relação a isso. Entre os sujeitos participantes da pesquisa, tanto encontramos aqueles que atuam somente no SUS quanto outros que buscam múltiplos vínculos como fontes de complementação de renda.

A carência de recursos humanos é apontada pelos médicos como uma das maiores causas de sobrecarga física e psíquica, além de uma permanente tensão. $\mathrm{O}$ planejamento da força de trabalho não acompanha o crescimento da população a ser atendida, seja pelos movimentos migratórios urbanos, como, por exemplo, pela inauguração de conjuntos habitacionais, aumentando em até 3000 pessoas a população de um determinado território, seja pelo aumento do desemprego, como aconteceu recentemente na história do país, levando os usuários de planos de saúde a recorrer ao SUS. "A sobrecarga de trabalho é muito grande, se eu abrir a porta, eu estou atendendo o tempo todo sem parar, eu não consigo parar de atender." (João $\left.{ }^{5}\right)$

Outra questão é a dificuldade, às vezes a impossibilidade, de repor trabalhadores em férias, exonerados ou demitidos (quando o vínculo é o contrato), ou licenciados por problemas de saúde. Diante do quadro incompleto de recursos humanos, delega-se aos trabalhadores que estão em serviço "cobrir" a ausência dos colegas. Nessas condições, falta o tempo necessário para o exercício do cuidado e os pacientes que deveriam estar sob acompanhamento contínuo ficam sem vaga, o que faz com que o atendimento, com frequência, seja insatisfatório, 
aos olhos dos médicos. Aí emerge o sentimento de frustração, em consequência da atividade impedida.

Trabalhamos com o conceito de atividade impedida tal como desenvolvido por Clot $(2001 ; 2010)$, como a amputação do poder de agir, o que significa o retraimento das capacidades e da autonomia sobre a atividade. Nesse sentido, revisitamos o conceito de real da atividade, incluindo não apenas a atividade realizada, mas também tudo o que não é feito, tudo o que poderia ter sido feito ou já não é feito mais, tudo o que se faz para fazer o que deve ou que não deve ser feito, ou ainda, o que se faz sem querer fazer. Dessa forma, a atividade contrariada, impedida, compõe esse transbordamento, esse excesso de impossibilidades e impotências, que restringe a percepção de um trabalho bem feito. Bem feito no sentido de reconhecer, na atividade, a eficácia que o sujeito deseja nela imprimir e de reconhecer-se, ele próprio, nesse fazer. Tanto quanto o excesso do que foi feito, o montante do que não foi feito causa fadiga, stress, desgaste (Clot, 2001; 2010). Observa-se que, frequentemente, os médicos têm que lidar com a sobrecarga de trabalho e de atividade impedida: "Eu já cheguei a trabalhar com quatro equipes, só eu. Sobrevivi [...] assim, isso frustra, porque às vezes você faz a programação toda pra cobrir seus hipertensos, seus diabéticos, aí cê tem que parar com tudo e ficar só com a demanda espontânea, que é o que você dá conta." (Marcos) ${ }^{6}$

Outro fator de desgaste refere-se à falta de medicamentos e insumos. $\mathrm{Na}$ atual condição de carência, percebe-se novamente a atividade impedida, pois os médicos não conseguem levar adiante a linha de tratamento necessária ao seu paciente. Josué ${ }^{7}$ se expressa da seguinte forma:

"Como eu falei, só quem tá aqui no dia a dia, conhecendo a realidade [...] tem paciente que não tem dinheiro pra comprar um comprimido de paracetamol. E aí?" (Josué)

Nesse sentido, destaca-se a necessidade dos médicos de serem inventivos para atuar no SUS, ao mesmo tempo que descrevem esse contexto de carência como ter que fazer "milagre" (Josué) ou como se eles tivessem que "plantar rosas no deserto" $\left(\right.$ Joana $\left.^{8}\right)$.

É certo que o medicamento não é o único instrumento que define a prática do médico. E isso foi posto em relatos de outros sujeitos, que chegam a afirmar que o remédio, muitas vezes, isoladamente, não dará o resultado esperado. Eles ressaltam a importância de incluir a escuta, o acolhimento, o afeto, que são outras formas de tratar as dores da solidão, do medo, da violência, das condições

6 Marcos atua no PSF de uma unidade de baixo risco há 13 anos.

7 Médico de uma unidade de muito elevado risco, há cinco anos atuando como médico de família.

8 Médica de uma unidade de muito elevado risco, atuando no PSF do SUS/BH há 14 anos. 
precárias de vida. Nesse sentido, mais uma vez identificamos o risco da atividade impedida, devido ao volume de atendimentos e ao tempo restrito das consultas, nem sempre sendo possível oferecer mais que uma receita.

Identificamos ainda o impacto das formas de gestão e das relações de poder no cotidiano dos centros de saúde. No caso do SUS, modelos de gestão que se caracterizam como violentos e intransigentes despontam vigorosamente em alguns espaços. Esses modelos parecem ser mais exigentes com os resultados quantitativos, que justifiquem recursos e investimentos e promovem visibilidade política, sendo menos exigentes com o uso ético e humanizado das tecnologias leves, leve-duras e duras, tal como definidas por Merhy (2004). Segundo esse autor, as tecnologias envolvidas nas práticas em saúde são caracterizadas por três diferentes dimensões: as tecnologias duras, relativas ao uso de equipamentos, exames e demais recursos instrumentais; as tecnologias leve-duras, que são os conhecimentos profissionais, saberes adequadamente estruturados; e as tecnologias leves, que representam o encontro, a troca intersubjetiva entre paciente e profissional, que envolve a escuta, a confiança e o vínculo. Para efetiva assistência à saúde humanizada e de qualidade, propõe-se assim a permeabilidade entre essas diferentes dimensões tecnológicas, do técnico ao não técnico (Ayres, 2004), e não a primazia de uma sobre outra.

Ao nos aproximarmos das vivências dos sujeitos em relação a essa questão, percebemos que, em casos de gestão autoritária, a ênfase no bem comum e na construção de redes solidárias de atenção e cuidado se dissipa em meio aos resultados e protocolos que se devem cumprir. As análises sugerem que onde os espaços deliberativos de construção compartilhada são substituídos pela resposta imediata à encomenda dos resultados, por parte da organização, manifesta-se, de forma mais evidente, o sofrimento, a insatisfação no trabalho e a necessidade de resistir.

Destaca-se a perda da autonomia do trabalhador como outro fator que pode levar ao sofrimento e/ou adoecimento. Por autonomia, entendemos o poder de agir, de decidir e transformar. Lhuilier (2006) afirma que o prazer no trabalho está ligado ao poder de ação, mas não no sentido da execução de tarefas. Tratase de uma ação na qual o sujeito se reconhece como protagonista de seu fazer, que lhe permite nela reconhecer-se e ser reconhecido pelo outro. Entre os médicos, percebemos que, em relação ao trabalho, ao fazer com seu paciente e suas demandas, eles se sentem autônomos, autores das arbitragens, decisóes e condutas, em parceria com os usuários, co-autores do processo de cuidado. Mas o mesmo não acontece no âmbito da organização dos processos de trabalho. A autonomia sobre a própria agenda, sobre o tempo de consulta, sobre a forma de organizar o trabalho, não é comum a todos os entrevistados, o que causa desânimo, insatisfação e, como resposta, também as transgressões. 
Clot (2007) destaca que um dos fatores deletérios do trabalho é a impossibilidade de fazê-lo com qualidade. E a qualidade, ou o trabalho bem feito, na avaliação do médico, poucas vezes corresponde aos números que a organização lhe demanda:

A demanda, eu falei que é uma demanda muito grande. $\mathrm{O}$ gestor, muitas vezes, não olha o lado do trabalhador, né? É número, número, número, é meta, meta, meta, e nisso a gente vai sendo assim, com a demanda do jeito que tá, cê acaba sendo engolido. No meio disso tudo, vem o desgaste emocional, vem o cansaço, o desgaste físico. (Josué)

A questão que se apresenta não recai sobre a necessidade de apresentar produtividade. Compreende-se sua importância, inclusive para o recebimento de verbas do Ministério da Saúde. Segundo os médicos entrevistados, a ênfase não deveria ser sobre o cumprimento da meta de cobrir $90 \%$ de atendimento de pacientes hipertensos, por exemplo, mas sim entender quantos estão efetivamente com a pressão arterial controlada.

As relações de trabalho também aparecem nos relatos como fonte de prazer ou sofrimento. Segundo Lhuilier (2013), o trabalho institui um intercâmbio social, uma vez que é sempre dirigido ao outro, é uma atividade endereçada, assumindo, assim, um caráter coletivo, ainda que exercido por um indivíduo. Nesse mesmo sentido, Dejours (2008) assinala que "trabalhar é viver junto", é estar inserido em um mundo compartilhado, democrático, de respeito mútuo. Entretanto, as transformações no mundo do trabalho, incluindo o trabalho no serviço público, vêm levando à deterioração das solidariedades, ao isolamento, à solidão vivida em conjunto. $\mathrm{O}$ atual contexto de constrangimentos, pressões e sobrecarga tem levado os trabalhadores a buscar saídas individuais, fragmentando cada vez mais os coletivos de trabalho.

Clot (2010) aponta a ausência dos coletivos de trabalho como outro fator que fragiliza o trabalhador, podendo levar ao sofrimento ou adoecimento. Ele marca a diferença entre trabalho coletivo, enquanto um conjunto de pessoas que trabalham juntas, porém solitárias; e o coletivo de trabalho, que é o resultado de uma história compartilhada do ofício, em que se desenvolve uma linguagem comum e as regras são construídas por todos. Nesse sentido, Joana observa:

Não tem brigas, conflitos, não é isso. Bom dia, boa tarde, almoça junto, ri das piadinhas, mas assim, eu acho que falta um fazer [...] um amálgama mesmo, que transforme numa coisa que é de todo mundo. Então eu acho que contribui, as relações superficiais, fragmentadas, contribuem também para o adoecimento, né? O isolamento. 


\section{CRIATIVIDADE E RESISTÊNCIA: ESTRATÉGIAS DE AÇÃO E SAÚDE}

Evidenciam-se, assim, muitos desafios com os quais os médicos lidam diariamente. $\mathrm{O}$ que os mantém em serviço, apesar do contexto, pode ser parcialmente nomeado estabilidade, vínculo, continuidade, mas há algo que escapa, que desliza pelas contradições e lacunas do discurso, que se refere à atividade, aquilo sobre o qual eles perseveram e que caracteriza os pontos de resistência que emergem no cotidiano.

Segundo Proust (1997), a resistência se exerce na adversidade. Ela não passa por um plano, uma ideia, ou mesmo pela razão: ela é "ato, conduta, gesto" (p. 49), resultado da indignação, afeto que leva o ser a se insurgir contra aquilo que lhe é insuportável. Daí a razão de a tomarmos em seu sentido de saúde, de força de vida, de potência e recurso para lidar com os imprevistos e indefinições do real da atividade e do trabalho real. Identificamos, a partir dos relatos, espaços em que as resistências, mais ou menos exitosas, se manifestam e criam novas configurações diante das relações de força e poder que se estabelecem no cotidiano de trabalho.

Segundo Lhuilier (2015), a impossibilidade de exercer o trabalho criativamente e, no nosso estudo, acrescentamos a atividade do médico tão frequentemente impedida, leva à criação de um falso selfe "impede o reconhecimento e o uso de si por sino trabalho" (p. 104). Temos, nesse caso, duas saídas possíveis:

a) a atividade impedida pode levar ao sofrimento e/ou ao adoecimento, ficando o sujeito aprisionado às prescrições, tendo seu trabalho reduzido a uma perspectiva apenas instrumental;

b) ou o despertar do exercício criativo da atividade, que viabiliza a transformação da tarefa, a renormalização, a reinvenção de si e do meio. Nesse caso, o trabalho pode ser ressignificado e seu sentido reconstruído.

Entre os médicos entrevistados, os relatos apontam movimentos de resistência que vão desde a transgressão a poderes instituídos, de forma nem sempre explícita, a intervenções no ambiente, nos consultórios, que acabam por produzir um efeito transformador sobre o dia a dia, na relação com o usuário dos serviços, com a organização e com a atividade. Eles desenvolvem ações que subvertem protocolos e normas, visando atender aos vínculos construídos e à responsabilização por cada família. Assim, surge um movimento novo, que inventa outras formas de vida e muda o curso da história (Proust, 1998). 
Emerge, nesse contexto, a criatividade no cotidiano, na forma de acolher o paciente, de debruçar sobre os casos, na relação que cada médico estabelece com o ofício e com toda a dinâmica envolvida na atividade, nas alternativas para lidar com as carências. $\mathrm{O}$ trabalho se apresenta como um ato desafiador, que promove a descoberta e a transformação das condições de vida de seus pacientes e deles próprios, enquanto médicos e enquanto sujeitos.

No que concerne a posicionamentos políticos e ideológicos, identificamos o caráter ambíguo da resistência em um dos relatos de João:

\begin{abstract}
Nunca [...] nunca fiz uma greve, tá? Porque [...] cê pensa bem: eu trabalho com uma população que eu entro dentro de casa. Compara as diferenças de condição: o indivíduo não pode vir aqui consultar[...] o menino está passando mal, não tem acesso, se vai pra UPA, tá superlotada, essa criança[...] eu atendi a todo mundo: cê conhece essa família que tá passando mal! Como é que eu paro, sabe? Ah [...] eu estou sendo contra a minha classe? Pode ser que sim. Mas o que é que é pior? Eu ir contra um monte de gente que tem mais condição, ou ir contra esse povo que às vezes não tem nada a ver com isso diretamente e que tá sofrendo? Então eu [...] eu opto por não fazer isto. Não sei até quando que eu vou dar conta de fazer isso também, porque é uma pressão danada, né?
\end{abstract}

Optar por não fazer greve pode parecer alienação diante das reivindicações de sua categoria, mas, visto de outra forma, ele resiste às pressões corporativas de classe, ainda que legítimas, para não deixar sua população sem atendimento. Pode-se interpretar essa conduta também como uma forma de resistência em nome do exercício de seu ofício e da validação de seus valores. Consideramos aqui o seu ofício como a ação de cuidar e de se responsabilizar por uma população vulnerável, com a qual construiu uma relação de confiança. Daí a resistência como "um misto de reatividade e atividade, de conservação e de invenção, de negação e de afirmação" (Proust, 1997, p. 11), o que nos leva, desde já, a apreender sua natureza ambígua e contraditória (Lhuilier e Roche, 2009).

Observamos ainda, em alguns sujeitos, um discurso que vai de encontro à lógica que tenta se impor como dominante, de que o SUS não funciona. Ao contrário, eles reiteram a todo momento, apesar das dificuldades, que acreditam na Atenção Primária e que uma das estratégias para lidar com as carências do sistema e contribuir com as mudanças necessárias é dar o melhor de si. De alguma forma, o poder que exercem a partir da construção de narrativas que imprimem relevância e qualidade ao SUS e à Atenção Primária vai de encontro a outros poderes, políticos e ideológicos, que alimentam o descrédito e a desqualificação da rede. 
Tais narrativas se convertem em ação, na medida em que se traduzem em gesto, em ato, no exercício de uma medicina de família de qualidade, em uma prática engajada em transformar a vida do outro e, por consequência, também a deles próprios. E talvez possamos identificar aí, a partir do discurso, outra forma de resistência. Ainda que nem todas as estratégias mencionadas nas entrevistas pareçam suficientemente efetivas, no sentido de preservar o bem-estar de forma plena, elas parecem suficientes pra sustentar o desejo de permanecer no SUS e manter-se em condição de saúde.

Joana, por exemplo, diante da precarização do trabalho, anuncia a impotência de mudar os mundos: o mundo do trabalho, o mundo da desigualdade, os diferentes mundos sem acesso aos determinantes sociais de saúde. E mesmo que a impotência seja por ela vista como adoecedora, não é o que a faz desistir de transformar, mesmo que em níveis mínimos, esses mundos. Assim, ela considera essencial a resistência de seus pacientes às condições árduas de existência, sobre a qual ela dispõe ou constrói recursos próprios para dizer não ao que é insuportável, ao que a levaria a não dar conta da vida e do trabalho no SUS:

Acho que o mais importante é o tanto que eu me inspiro naquelas pessoas, com recursos poucos, darem conta da vida, sabe? Apesar de muito pouco. [...] Enquanto trabalhadora eu tenho às vezes muito menos do que eu preciso, e assim, elas dão conta da vida em lugares [...] que se acha [...] que podia desistir. Então eu acho que isso aí é a minha principal fonte de inspiração e de resistência. São os meus pacientes com a vida deles e como eles dão conta da vida em condições super inóspitas, entendeu? Não que eles tenham que se resignar com isso. Eu acho que tem que gritar, brigar e melhorar as condiçōes de vida porque é direito, assim como a gente. Eu acho que assim a gente tem que gritar, brigar, melhorar as condiçōes de trabalho, condições de salário, as relaçōes, eu acho que resistir não significa aceitar. Mas é isso que é a minha fonte de resistência. São essas pessoas e a vida delas.

Diante do que lhe causa indignação, Joana destaca o caráter essencialmente político da resistência. Outros médicos relatam outras estratégias, transgressões, quebras de protocolos, astúcias e subversão de normas, que possibilitam que o trabalho aconteça e o cuidado se imponha, ainda que não em sua potencialidade máxima, mas na potencialidade possível.

\section{CONSIDERAÇÕES FINAIS}

É certo que os sujeitos da pesquisa não representam a totalidade dos médicos do PSF. O engajamento e o sentido do trabalho não são os mesmos para toda a comunidade de médicos do PSF da rede SUS. Mas deve-se destacar o movimento de tirar da invisibilidade aqueles que lutam e se dedicam à sobrevivência do SUS, agindo em consonância com os princípios, diretrizes e valores democráticos e solidários da Reforma Sanitária. 
Seja pelo engajamento político, pelas transgressões, pela ancoragem no coletivo ou mesmo pelas saídas individuais, as estratégias de resistência apontam que o trabalho não comporta ações e posicionamentos estáveis ou estáticos. Nesse dinamismo da atividade, emergem acontecimentos, nem sempre previsíveis, para os quais é necessário criar alternativas de resistência, fazer um uso de si que reconfigure as interaçóes com o meio e com o outro. O cotidiano das Unidades Básicas de Saúde convoca o movimento criativo, que transita entre a negociação, o enfrentamento e, em alguns momentos, também a submissão.

Identificamos nesses relatos o laço entre trabalho, resistência e saúde. Os debates que se impõem no dia a dia dos médicos, entre a expertise médica e o engajamento ético-político, promovem o movimento da renormalização, dos enfrentamentos com o real da vida e do trabalho. $\mathrm{O}$ movimento dialético entre os valores dos sujeitos, os valores da organização ou dos pacientes, entre o compromisso com a ciência e com a verdade de cada sujeito que se apresenta nos consultórios, faz com que reinventem formas de se posicionar, de escutar, acolher e cuidar. Como afirma Lhuilier (2012), trata-se de ampliar o olhar das condições de trabalho para as "relações subjetivas à situação de trabalho e à atividade [...]" (p. 21). Nesse sentido, a saúde não significa estar submisso à normalidade social, mas sim abrir perspectivas de negociação com o meio, a fim de encontrar margens de manobra e equilíbrio que permitam ao sujeito criar seu contexto (Lhuilier \& Roche, 2009; Canguilhem, 2007). 


\section{REFERÊNCIAS}

Arouca, S. (2003). Entrevista: Sérgio Arouca. Entrevista concedida a Ana Beatriz de Noronha, Caco Xavier, Daniela Sophia, Katia Machado \& Rogério Lannes Rocha. Trabalho, Educação e Saúde, 1(2). Recuperado a partir de http://www. scielo.br/pdf/tes/v1n2/10.pdf

Ayres, J. R. C. M. (2004, setembro, dezembro). O cuidado, os modos de ser (do) humano e as práticas de saúde. Saúde e Sociedade. 13(3), 16-29. Recuperado a partir de http://dx.doi.org/10.1590/S0104-12902004000300003

Bampi, L. (2002). Governo, subjetivação e resistência em Foucault. Educação \& Realidade. 27(1),127-150.

Bardin, L. (2011). Análise de conteúdo. L. A. Reto \& A. Pinheiro (Trads.). São Paulo: Ed. 70.

Brasil. (2012). Ministério da Saúde. Política Nacional de Atenção Básica. Brasília: Ministério da Saúde. (Série E. Legislação em Saúde). Recuperado a partir de: http://dab.saude.gov.br/portaldab/biblioteca.php?conteudo=publicacoes/ pnab.

Canguilhem, G. (2007). O normal e o patológico. M. T. R. C. Barrocas (Trad. 6a ed.). Rio de Janeiro: Forense Universitária.

Clot, Y. (2001). Clínica do trabalho, clínica do real. Le journal des psychologues. (185). K. Santorum \& S. L. Barker (Trads.). Recuperado a partir de http:// www.pqv.unifesp.br/clotClindotrab-tradkslb.pdf

Clot, Y. (2007). Pour le travail, contre le travail, au-delà du travail. In: J. P. Gelard. Travailler plus travailler moins travaieller autrement. Rennes: Presses Universitaires de Rennes.

Clot, Y. (2010). Trabalho e poder de agir. G. J. de Freitas \& M. M. Z. Viana (Trads). Belo Horizonte: Fabrefactum.

Dejours, C. (2008). Addendum. In S. Lancman, \& L. I. Sznelwar (Orgs). Christophe Dejours: da psicopatologia à psicodinâmica do trabalho. (pp. 49-106). Rio de Janeiro: Fiocruz.

Fleury, L. (2009). Affects et résistance: le cas 'Wiesler' dans la vie des autres. Nouvelle Revue de Psychosociologie, 1 (7), 49-70. 
Lhuilier, D. (2006). Travail. In J. Barus-Michel; E. Enriquez; A. Lévy (Orgs). Vocabulaire de Psychosociologie: positions et references. Ramonville Saint-Agne: Ed. Érès, pp. 275-286.

Lhuilier, D. \& Roche, P. (2009). Introduction. Nouvelle Revue de Psychologie, (7), 7-18.

Lhuilier, D. (2012). A invisibilidade do trabalho real e a opacidade das relações saúde-trabalho. Trabalho \& Educação. 21(1), p. 13-38. Recuperado a partir de http://seer.ufmg.br/index.php/trabedu/article/view/7222.

Lhuilier, D. (2013). Trabalho. Psicologia \& Sociedade, 25(3), 483-492.

Lhuilier, D. (2015). Puissance normative et créative de la vulnérabilité. Education Permanente (dossier Travail et Créativié), (202), 101-116. Paris/Arcueil.

Maciel Júnior. A. (2013). Resistência e prática de si em Foucault. Rio de Janeiro: UVA. Recuperado a partir de http://www.uva.br/trivium/edicoes/edicao-iano-vi/artigos-tematicos/artigo-tematico-1.pdf

Merhy, E. E. (2004). O ato de cuidar: a alma dos serviços de saúde. Ver-SUS Brasil: caderno de textos, 108-137. Brasília: Ministério da Saúde. Recuperado a partir de https://www.nescon.medicina.ufmg.br/biblioteca/imagem/2103.pdf

Minayo, M. C. S. (2010). O desafio do conhecimento: pesquisa qualitativa em saúde. (12a ed.). São Paulo, SP: Hucitec.

Proust, F. (1997). De la résistance. Paris, França: Éditions du Cerf.

Proust, F. (1998). Résistir à l'irresistible. Entretien avec Daniel Bensaid. Le site Daniel Bensaid. Rétabli http://danielbensaid.org/Resister-a-1irresistible?lang=fr

Proust, F. (2000). Introduction to de la résistance. Hypatia, 15 (4), 18-22.

Rates, S. M. M.; Teixeira, M. G.; Almeida, M. C. M.; Silva, H.; Gomes, D. H. P.; Alves, G. M. P.; Pitchon, A. (2012). Projeto para implantação de Equipes de Saúde da Família para a população vulnerável não coberta com a Estratégia do Programa de Saúde da Família - Secretaria Municipal de Saúde de Belo Horizonte. In M. G. Teixeira; S. M. M. Rates \& Rates; J. M. Ferrei (Orgs). O coletivo de uma construção: o Sistema Único de Saúde de Belo Horizonte. (Vol. 1, pp. 68-74). Belo Horizonte: Rona. 
Schwartz, Y. (2011). Manifesto por um ergoengajamento. In: P. F. Bendassolli \& L. A. P. Soboll (Orgs.). Clínicas do trabalho: novas perspectivas para a compreensão do trabalho na atualidade, p. 132-166. São Paulo: Atlas.

Tostes, M. L. F., Reis, J. C. \& Pitchon, A. (2012). A coordenação do cuidado pela atenção primária no SUS-BH. In M. G.Teixeira; S. M. M. Rates, \& Rates; J. M. Ferreira, (Orgs). O coletivo de uma construção: o Sistema Único de Saúde de Belo Horizonte. (Vol. 1, pp. 148-156). Belo Horizonte: Rona. 